\title{
Associations Between Emotions, Social Media Use, and Sun Exposure Among Young Women: Ecological Momentary Assessment Study
}

Jessica Fitts Willoughby ${ }^{1}, \mathrm{PhD}$; Jessica Gall Myrick ${ }^{2}, \mathrm{PhD}$; Stephanie Gibbons ${ }^{1}$, MA; Clark Kogan ${ }^{3}, \mathrm{PhD}$

\footnotetext{
${ }^{1}$ The Edward R Murrow College of Communication, Washington State University, Pullman, WA, United States

${ }^{2}$ Donald P Bellisario College of Communications, Pennsylvania State University, University Park, PA, United States

${ }^{3}$ Center for Interdisciplinary Statistical Education and Research, Washington State University, Pullman, WA, United States
}

\section{Corresponding Author:}

Jessica Fitts Willoughby, $\mathrm{PhD}$

The Edward R Murrow College of Communication

Washington State University

208 Goertzen Hall

PO Box 642520

Pullman, WA, 99164-2520

United States

Phone: 15093357926

Email: jessica.willoughby@wsu.edu

\section{Abstract}

Background: Research has pointed to a connection between social media use, emotions, and tanning behaviors. However, less is known about the role specific emotions may play in influencing social media use and how emotions and social media use may each be associated with outdoor tanning.

Objective: This paper aims to examine the connection between emotions, social media use, and outdoor tanning behaviors among young women, a group particularly important for skin cancer prevention efforts.

Methods: We used ecological momentary assessment to collect data from 197 women aged 18 to 25 years 3 times a day for 7 days in July 2018. We collected data from women in 2 states.

Results: We found that boredom was associated with increased time spent on social media and that increased time spent on social media was associated with increased time spent outdoors without sun protection.

Conclusions: Our results highlight that social media may be a particularly important channel for skin cancer prevention efforts targeting young women, as more social media use was associated with increased time spent outdoors with skin exposed. Researchers should consider the role of emotions in motivating social media use and subsequent tanning behaviors. Additionally, as boredom was associated with social media use, intervention developers would benefit from developing digital and social media interventions that entertain as well as educate.

(JMIR Dermatol 2020;3(1):e18371) doi: $\underline{10.2196 / 18371}$

\section{KEYWORDS}

social media; skin cancer; emotions; cancer prevention; health communication; ecological momentary assessment

\section{Introduction}

\section{Background}

It is estimated that more than 100,000 new cases of melanoma, the deadliest type of skin cancer, will be diagnosed in the United States in 2020 [1], and melanoma is one of the most prevalent cancers in young women [2]. Younger skin is particularly vulnerable to the effects of ultraviolet light and the skin damage it may cause [3]. Despite the health implications of exposure to ultraviolet light, young women often express a desire to have tan skin and believe having a tan makes them look healthier [4]. Taken together, these statistics and preferences point to an increased risk of skin cancer among young women.

As such, researchers are eager to better understand the psychosocial and behavioral factors that predict risky skin behaviors like tanning. Previous research has found that 
emotions are associated with indoor tanning behaviors in young women [5], as is young women's use of social media [6]. Additionally, research has found that intentional outdoor tanning is significantly greater among girls who spend more time on their cell phones [7].

One psychosocial predictor that may help predict tanning is emotions, which may be particularly important for understanding both media use and tanning behaviors for a number of reasons. Appraisal theory suggests that specific emotions may be linked with action tendencies based on automatic subjective evaluations [8]. For example, a person experiences happiness when they have gained something they desire. The action tendencies associated with happiness include moving toward the happiness-inducing event, sharing positive outcomes, and celebration [8,9]. However, there is a lack of understanding about the role different emotions might play in motivating social media use and outdoor tanning, a risk behavior related to skin cancer.

In this manuscript, we examine the associations among emotions and social media use, emotions and risky outdoor skin behaviors, and social media use and outdoor tanning behavior using ecological momentary assessment. This method allows us to see how emotions, media use, and tanning behavior interrelate in real time throughout the course of a week. This may be important, as previous research has found that emotions vary throughout the day in response to stressors (eg, minor hassles that happen throughout the day in people's lives) [10]. Therefore, capturing emotion data at a single point in time may substantially increase the noise, thereby reducing the power. Additionally, digital media use is often frequent and dynamic, leading to challenges in determining how to best measure media exposure [11]. Previous research in other topic areas has found that retrospective self-report in communication may be difficult [12]. As the use of ecological momentary assessment is beneficial for collecting data and may better assess complex or dynamic data [13], we used 3 daily surveys over the course of a week to assess social media use, emotions, and related outcomes among young women.

\section{Emotions and Social Media}

Research has unearthed both positive and negative consequences of using social media, warranting a perpetual need to understand the evolving media platform [14]. A great deal of social media research has focused on the linear effect that social media may have on one's emotions $[15,16]$. This includes outcomes such as increased depression, anxiety, need of belonging, empathy, social desirability, social support, and others. However, the relationship between social media use and one's emotions is often cyclical, with certain emotions and personality types perpetuating social media consumption [14].

For example, rather than observing how social media use leads to loneliness, it is important to also observe that users turn to social media as a substitute for social interaction [16]. Certain personality traits and emotions, such as extroversion and levels of instability, are associated with social media use and willingness to interact [17]. Forgas [18] argues that emotions influence every aspect of an individual's life and stimulate each behavior in some aspect. As such, emotions influence social media use, too. Motives for social media use are unique, since they encompass "a diverse and complex set of (often unconscious) decision-making activities, influenced by a large number of individual, collective, and environmental factors" [14]. Positive outcomes of social media use include entertainment or connectivity, while negative emotional outcomes may include users' feelings that they are wasting time or distracting themselves from more meaningful social interaction [14]. These emotional experiences have been shown to predict social media use, especially with regard to information sharing, entertainment, and convenience [19-21]. Research has found that young adults use social media for a variety of reasons, including information [22], entertainment and leisure [23], socialization [24], and keeping in contact with others [23]. The previously discussed research leads to our first research question (research question 1): Which emotions are associated with the increased use of social media among young women?

\section{Emotions and Tanning}

Many individuals have positive emotional associations with the sun [25]. In fact, researchers have identified a physiological link between exposure to UV light and the feel-good chemicals released by our bodies, called endorphins [26]. As such, it may not be surprising that ultraviolet exposure can make people feel good. Expectations or beliefs that tanning will result in a positive emotional state have been consistently found to predict both indoor and outdoor tanning [27-29]. Conversely, individuals who have negative emotional associations with tanning (eg, they think they will be uncomfortable while doing it or are anxious about the health risks) are less likely to perform the behavior [30].

According to the broaden-and-build theory, positive emotions exist to motivate individuals to broaden the scopes of their attention and skills while also building resources and relationships to help them cope with future negative situations [31]. Tanning is often a social activity done with friends and reported to be an enjoyable, positive experience [25]. However, positive emotions can also reinforce behaviors that elicit them, even if individuals know the behavior is risky [32]. As such, the positive emotional association that individuals build with tanning behaviors may continue to motivate them to pursue this cancer-causing behavior to maintain a positive emotional state or alleviate a negative one.

This supposition is also in line with mood management theory, which argues that people often seek stimuli (be it a behavior or a media message) that help them achieve a more positive mood $[33,34]$. For example, recent work using the National Cancer Institute's Family Life, Activity, Sun, Health, and Eating (FLASHE) cross-sectional survey found that adolescents who reported being frequent outdoor tanners were more likely to experience loneliness than adolescents who reported they did not tan outdoors [7]. Although more research is needed to understand this relationship, it could be that adolescents in the survey tanned outdoors in order to reap the positive emotional benefits that could help them cope with feelings of loneliness. This lack of clear consensus around the role of positive emotions and tanning behaviors led to the following research question (research question 2): Are more positive emotions associated 
with increased time spent outdoors without sun protection among young women?

\section{Social Media and Tanning}

Although there is some understanding of how social media may influence well-being, researchers have called for more research to be conducted related to digital natives and social media's impact on behavior, health, and society [23]. Research has found that media use is connected to a variety of tanning behaviors $[4,6,35,36]$. Of particular note, young women may desire to look like people in the media [37]. In US culture, tan skin is a commonly held beauty standard, and women often engage in outdoor or indoor tanning to achieve this standard. Although previous research has observed how media sources such as television [38] and magazines [35,36] influence tanning behaviors, a recent focus has been on social media [6,7]. Social media expands on traditional media platforms, as there are greater opportunities to interact within the media and exchange images. Additionally, social media is a channel frequently used by young women [39]. Social media has been found to have an indirect but positive relationship with indoor tanning use among young women, while traditional mass media has not [5]. Such research purports that social media may perpetuate the desire to engage in tanning behaviors $[5,40]$.

A theoretical rationale for the effects of social media on tanning behaviors comes from social cognitive theory [41,42], which posits that people can learn from behaviors modeled in media. Although media may not always directly model tanning behavior, people who are rewarded or viewed positively and are tan could influence young women to aim to achieve a similar look. Social media has been found to be related to the belief that indoor tanning leads to positive outcomes, such as improved appearance, greater mood, and improved health, while simultaneously being negatively associated with health and social consequences [5].

In part, this relationship may also have to do with the connections and relationships that can occur around tanning. Researchers have found tanning to be a social experience, as indoor tanners are likely to discuss tanning with friends [43]. In a study that looked at different platforms and their connections to tanning behaviors, Willoughby and Myrick [6] found that image-based social media platforms, such as Snapchat, Instagram, and Pinterest, were all positively associated with sunbathing, suggesting that the inclusion of images of tanned or tanning people may encourage young women to spend time sunbathing. Based on the previously discussed literature, we propose the following hypothesis: Increased social media use will be associated with increased time spent outdoors without sun protection among young women.

\section{Methods}

\section{Study Design}

We conducted an ecological momentary assessment (EMA) of young women's emotions, social media use, and outdoor tanning behaviors over a 7-day period in July 2018. EMA is a data collection method that allows for real-time data collection. It uses mobile devices to ask participants to report on moods or behaviors at specific points in time close to when the events occurred. Consequently, EMA has potential advantages over traditional data collection methods, including its usefulness for measuring mood and behavior [44].

\section{Recruitment}

Participants were recruited from 2 universities in the United States, one in the Pacific Northwest and one in the Northeast. A mix of in-person and online methods were used to recruit young adult college women at the participating universities. If they were interested and met inclusion criteria (ie, identified as a woman and were aged 18-29 years), participants signed up via a text message program to receive study updates. All participants received the EMA over the same 7-day period in July 2018.

\section{Procedures}

Participants received 3 messages a day. The first assessment was sent at $10 \mathrm{AM}$ and asked participants about their current emotions. The second assessment was sent at 4 PM and asked about social media use over the past 6 hours, time spent outdoors, and current emotions. The third assessment was sent at $8 \mathrm{PM}$ and asked about social media use over the past 4 hours, current emotions, time spent outdoors, and the weather. We selected the timing of the surveys to fall around peak UV exposure, which occurs between 10 AM and 4 PM [45], with an end time of $8 \mathrm{PM}$ to avoid having the surveys sent too late in the evening for some participants. At the end of the week, participants were asked to complete a longer survey that asked about demographics, attitudes, and behaviors. For completing at least half of the EMA surveys and the posttest, participants received US \$50 in cash. Prior to conducting the research, the first author's institutional review board approved all procedures.

\section{Measures}

Individual emotions were measured at 3 time points by asking participants to "rate how much of each emotion describes how you are feeling" on a 5-point Likert-type scale from "none of this emotion at all" to "a great deal of this emotion." The emotions assessed included the following: content, excited, sad, envious, anxious, and bored. We selected these specific emotions based on previous research that examined emotions and tanning $[27,46,47]$. We examined both the discrete emotions and a composite measure of positivity. Composite measures of positivity have been used in previous research [48]. We created the composite measure to indicate whether a person was experiencing a greater level of positive emotions by adding together contentment and excitement and then subtracting sadness, envy, anxiety, and boredom. The emotions data were summarized to obtain the average of each emotional state over all 7 days and over all 3 time points. The creation of the composite measure is similar to composite creation measures in other work on emotion regulation [49].

Social media was measured at 2 time points daily (second and third survey) with the question "How often have you used the following social media since the last survey?" on a slider scale with half-hour increments marked. The options were Instagram, Facebook, Twitter, Snapchat, and text messaging. As we were focused on the role of social media collectively for this study, 
we added together the amount of time participants reported spending on Instagram, Facebook, Twitter, and Snapchat. We calculated the sum of the hours spent on social media over the day divided by the proportion of the daily hours that were observed via survey response. For instance, if only morning social media usage was recorded, then the total amount of time on social media was divided by 0.6 , as the time period represents $60 \%$ of the time participants reported social media use. If participants responded to both surveys, then it would be the total number of hours observed that day.

Sun exposure was measured with the question "How much time did you spend outdoors with your skin exposed?" on a slider scale with half-hour increments marked at both 4 PM and 8 PM. If there was an observation at $8 \mathrm{PM}$ but no observation at $4 \mathrm{PM}$ (missing data), we used the amount of time outdoors divided by 0.4 (as the 4 PM to 8 PM time period represents $40 \%$ of the overall time they were questioned about outdoor tanning). If data were available at both times, we summed the amount of time to determine total time outdoors. The time periods used were selected because they encompass the peak sun hours in which participants could have spent time outdoors. The item is similar to items used in previous research that considered time spent outside without sun protection as a measure of sun exposure [50,51], but it included specific time frames to take advantage of the multiple measurements in EMA.

Perceived weather was measured with 3 items that asked participants to "please indicate how strongly you disagree or agree with the following statements regarding the weather today" on a 5-point Likert-type scale: "It was sunny outside," "It was warm outside," and "The weather was nice." We averaged the 3 weather variables to obtain a new weather variable that indicated whether the weather was nice (Cronbach $\alpha=.853$ ).

\section{Analysis Strategy}

We collected data from 197 individuals, but due to missing data, we had 192 participants in the data frame that was used to address research question 1 and 179 participants in the data frame that was used to address research question 2 .

To assess research question 1 , which asked which specific emotions were associated with increased use of social media, we fit a linear model relating the logarithm of the average daily amount of time (out of the 10 hours assessed) that participants used social media to the average emotional state of an individual. Emotions were included in the regression using natural cubic splines in order to allow for a nonlinear relationship between the emotional scale and the log of the social media usage. We computed an adjusted generalization of the Spearman rank correlation to motivate the number of knots to use for each cubic spline. Correlations between each emotion and overall social media use were small for all variables except boredom. We therefore considered a restricted cubic spline for boredom (with
3 knots) and included all other terms as linear. Between 3 and 5 knots is typically found to be sufficient for a spline, and as our correlation between boredom and social media use was only moderate, 3 knots was selected [52]. We constructed residual plots to assess the plausibility of the normality and variance homogeneity assumption and found little evidence to suggest major deviation. Wald $F$ statistics were computed to summarize the effect of each emotion on social media use.

To assess research question 2, which asked if increased positive emotions were associated with increased time spent outdoors without sun protection, and hypothesis 1 , which posited that increased use of social media would be associated with increased time spent outdoors without sun protection, we performed a generalized least squares regression to relate daily time outdoors to positivity and social media use after adjusting for weather and accounting for correlation within individuals via the use of a compound symmetric correlation structure. As all correlations between variables were very small, we considered only linear terms in our regression analysis. We prefer generalized least squares to mixed-effects modeling, as it has a certain elegance for continuous responses [52]. We used the square root transformation for the time spent outdoors to help improve the plausibility of residual normality. Residuals were assessed for the plausibility of normality and variance homogeneity. Mild deviations from normality were found, but they were not substantial enough to warrant further transformations or a change in the distributional assumptions. Furthermore, there was little evidence to suggest more than minor deviations from variance homogeneity. We conducted Wald tests to assess the overall effect of positivity, weather, and social media on time spent outdoors.

\section{Results}

\section{Sample}

We collected demographic information at the end with a posttest survey $(\mathrm{N}=149)$. Some people did not respond to all surveys; as such, we examined the sample descriptive statistics by each analysis frame for comparison, finding minimal differences. We report on the descriptive data for individuals who completed the posttest survey.

On average, participants were aged 20.5 (SD 6.81) years. A total of $69.8 \%(104 / 149)$ of participants were from Washington state, and 26.2\% (39/149) of participants were from Pennsylvania; $4.0 \%(6 / 149)$ reported being from another state. Nearly two-thirds $(110 / 149,73.8 \%)$ of participants reported being White or Caucasian. The majority of participants reported spending time outdoors in the sun a few times per week $(65 / 149$, $43.6 \%)$ or once per week $(31 / 149,20.8 \%)$. In addition, $36.2 \%$ $(54 / 149)$ of participants had indoor tanned at some time in their life. Table 1 presents additional demographic information. 
Table 1. Demographic information of study participants.

\begin{tabular}{|c|c|}
\hline Variable & Participants, $\mathrm{n}(\%)^{\mathrm{a}}$ \\
\hline \multicolumn{2}{|l|}{ Race } \\
\hline White or Caucasian & $110(74)$ \\
\hline Asian or Pacific Islander & $19(13)$ \\
\hline Hispanic or Latina & $16(11)$ \\
\hline Black or African American & $9(6)$ \\
\hline American Indian or Native American & $4(3)$ \\
\hline Other & $1(1)$ \\
\hline \multicolumn{2}{|l|}{ Grade } \\
\hline Freshman & $37(25)$ \\
\hline Sophomore & $19(13)$ \\
\hline Junior & $42(28)$ \\
\hline Senior & $39(27)$ \\
\hline Other or not applicable & $12(7)$ \\
\hline Not diagnosed with skin cancer & $149(100)$ \\
\hline Someone close ever diagnosed with skin cancer (yes) & $64(43)$ \\
\hline \multicolumn{2}{|l|}{ Area in which they live } \\
\hline Rural (eg, in the country) & $44(30)$ \\
\hline Urban (eg, in the city) & $20(13)$ \\
\hline Suburban (eg, near a city, outside a city) & $79(53)$ \\
\hline Indoor tan ever (yes) & $54(36)$ \\
\hline
\end{tabular}

${ }^{\mathrm{a}}$ Descriptive data included 149 individuals, as some participants did not complete the posttest questionnaire.

\section{Research Questions and Hypothesis Testing}

For research question 1, we found evidence suggesting an association between one or more emotions and social media use $\left(F_{7,184}=5.94 ; P<.001\right)$. Specifically, boredom was associated with increased social media use $\left(F_{2,7}=14.70 ; P<.001\right)$. To interpret the effect size of boredom, we fit a simplified model in which boredom was reduced to a linear effect. We found an estimated increase of $67 \%$ (95\% CI 37\%-103\%) in social media usage for every 1-unit increase in boredom (Figure 1). We assessed the evidence that the effect of boredom on social media use was nonlinear and found no evidence against linearity $(P=.10)$. We did not find evidence that levels of contentment, excitement, sadness, envy, or anxiousness were associated with social media use with the current sample (Table 2).

Figure 1. Average daily social media use (in hours) plotted against average boredom. The blue line shows the model predictions after back transformation across different boredom ratings, computed at the mean value for all other emotions.

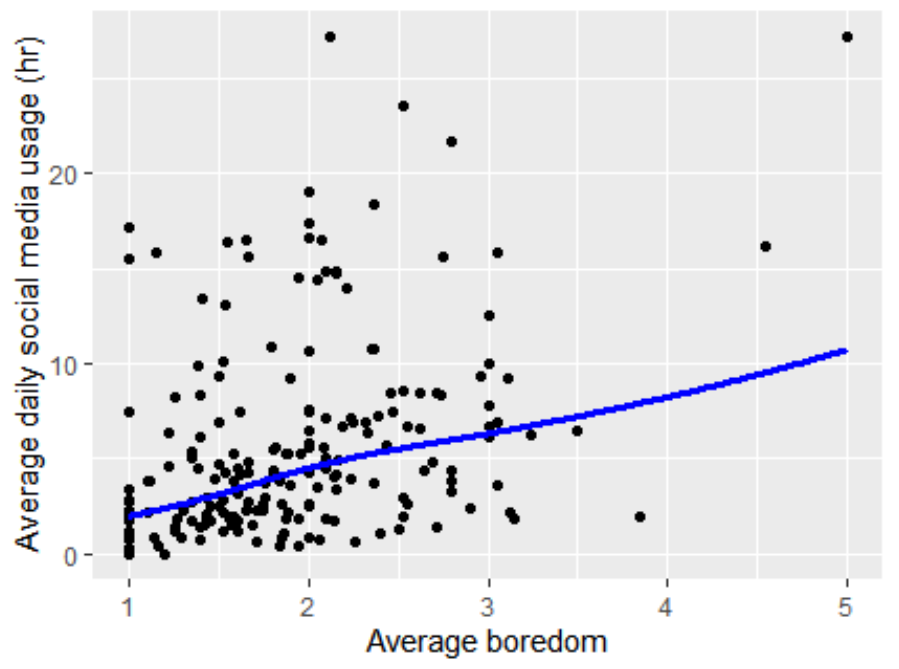


Table 2. Social media use analysis of variance.

\begin{tabular}{|c|c|c|c|c|}
\hline Emotion & Partial sum of squares & Mean squares & $F$ value $(d f)$ & $P$ value \\
\hline Bored & 23.80 & 11.90 & $14.70^{\mathrm{a}}(2)$ & $<.001$ \\
\hline Content & 0.53 & 0.53 & $0.66(1)$ & .42 \\
\hline Excited & 0.94 & 0.94 & $1.16(1)$ & .28 \\
\hline Sad & 0.38 & 0.38 & $0.46(1)$ & .50 \\
\hline Envious & 1.42 & 1.42 & $1.76(1)$ & .19 \\
\hline Anxious & 0.34 & 0.34 & $0.41(1)$ & .52 \\
\hline
\end{tabular}

${ }^{\text {a }}$ Significant at the $P<.001$ level.

For research question 2, there was evidence suggesting some association between time spent outdoors and the explanatory variables of positivity, weather, and social media $(\mathrm{N}=184$; $\left.\chi_{3}^{2}=17.9 ; P<.001\right)$. Further Wald tests found slight evidence of

an effect of positivity $(P=.08)$ and strong evidence for a modest effect of social media $(P<.001)$ on time spent outdoors without sun protection, providing support for hypothesis 1 (Figure 2 and Table 3).

Figure 2. Average daily time outdoors (in hours) plotted against average daily social media use. The blue line shows the model predictions after back transformation across different social media usage levels, computed at the mean value for positivity and weather.

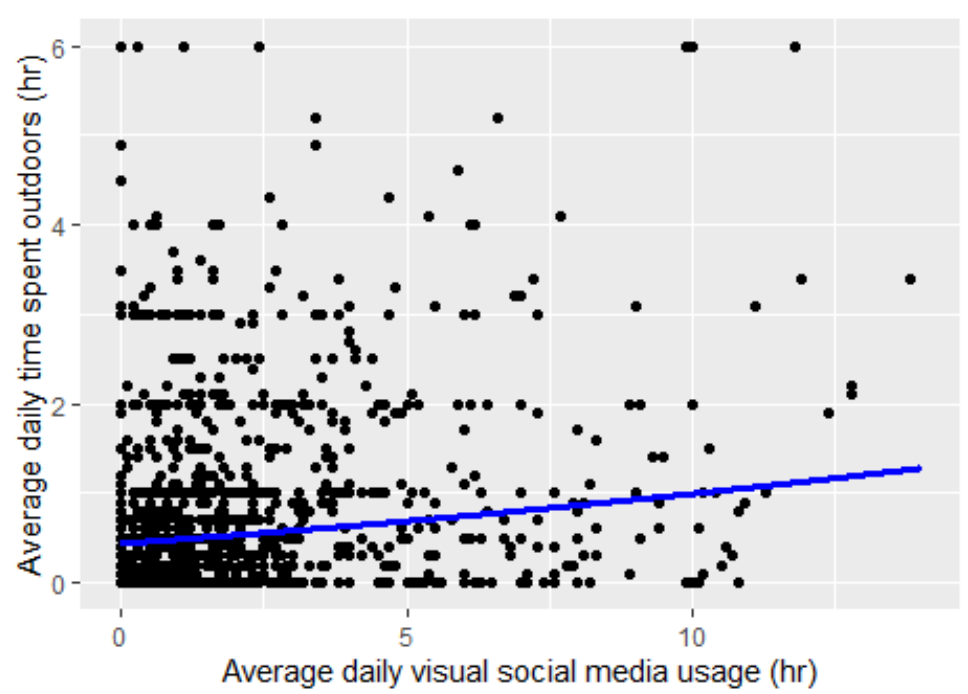

Table 3. Results of Wald analysis of variance on increased amount of time spent outdoors.

\begin{tabular}{lll}
\hline Factor & Chi-square $(d f)$ & $P$ value \\
\hline Positivity & $3.1(1)$ & .08 \\
Weather & $3.7(1)$ & .06 \\
Social media & $13.9(1)$ & $<.001$ \\
\hline
\end{tabular}

\section{Discussion}

\section{Principal Findings}

This research used an EMA study conducted with young women over the course of a week in July to assess the relationships between emotions, social media use, and time spent outdoors. Of the emotions we assessed, we found only boredom associated with increased use of social media, with increased reports of boredom associated with increased time spent on social media. The magnitude of the effect was substantial, with boredom at greater levels nearly doubling social media use. Additionally, increased use of social media was significantly associated with increased time spent outdoors without sun protection. Below, we discuss these findings in greater depth.

Boredom, a low-arousal negative emotional state, occurs when an individual is unable or unwilling to dedicate their attention to whatever is currently in front of them [53]. Another definition of boredom is monotony combined with frustration [54]. Individuals experiencing boredom have been found to visit more websites during an internet search task than overstimulated, stressed individuals [55]. In our study, increased levels of boredom were associated with increased social media use, highlighting how individuals may use social media as a distraction or way to entertain themselves [23]. If bored individuals turn to social media that portray tan celebrities and 
peers, it could then motivate them to tan as another means of shifting their emotional state to something more pleasant.

Of the other emotions we assessed, including contentment, excitement, envy, anxiety, and sadness, none were significantly associated with social media use in our analyses. There may be a few different reasons for this. First, according to the appraisal theory of emotions, different emotions predispose people to take certain actions (called action tendencies) [8]. However, those action tendencies are typically directed at the underlying cause of that emotion. For example, if an individual is afraid of skin cancer, the action tendency is to avoid the threat somehow (possibly by not tanning). Since we measured emotions more generally (ie, not directly related to tanning), they may have predicted a number of potential actions more generally too. Future work could collect emotional responses with a specific target.

Second, previous research has found that the use of specific social media sites (ie, Facebook) for surveillance was associated with depression, with envy mediating the relationship. However, no direct effects between social media use and depression were found [56]. Additional research has found similar links, with envy and social comparison mediating the association between Facebook use and depression [57]. As these studies highlight, there are potential mediators and moderators that may be associated with social media use and emotions. Perhaps different, unaccounted for variables could help connect emotions to social media.

Lastly, it is possible that, as we used 3 daily surveys 4 or more hours apart, our time measurement wasn't specific enough to see the resulting impact of emotions on social media use except with boredom, which provided a strong enough result to lead to increased social media use at the time of measurement. Future research could benefit from varying the timing to see if emotions then impact resulting social media use.

In addition to finding an association between boredom and subsequent social media use, we found that increased use of social media was associated with increased time spent outdoors without sun protection. This supports previous research, which has found a connection between social media and tanning behaviors [5-7]. Americans frequently use social media, with young adults (aged 18-24 years) using a variety of platforms and most of them $(71 \%)$ visiting the platforms multiple times each day [39]. Nearly 3 out of 4 young people use Instagram, a highly visual form of social media, with young women often reporting frequent use. The content to which young women are exposed could be showcasing the benefits of tanning behaviors. In line with social cognitive theory [42], when individuals see behaviors that are modeled and rewarded, they may be more likely to engage in such behaviors. Additionally, as peers and socialization may impact tanning behaviors [43,58], social media may play an especially important role. This supports other research that has highlighted the possibility of using social media for skin cancer prevention efforts [59].

Taken together, these findings have implications for skin cancer prevention strategies among young women. In particular, social media is a well-suited platform for prevention efforts, as individuals who spend time in the sun without sun protection are also likely to use social media. Additionally, as young women turn to social media when bored, strategies that employ some form of entertainment may be particularly well suited to engaging the audience and garnering attention toward prevention efforts. Strategies such as entertainment education, which is the inclusion of educational content in entertaining formats [60], have been found to be effective for a variety of health topics related to risky behaviors [61,62]. Entertainment education efforts targeting young women in digital media have been found to be effective at influencing elements of narrative that may lead to behavior change, such as transportation and engagement $[63,64]$. As young women may be turning to social media when bored, including prevention efforts that entertain while also educating may help by first garnering attention, which can be difficult in the crowded social media environment. A recent meta-analysis of narrative game-based health behavior interventions found that such interventions had a large effect on improving knowledge, a medium effect on self-efficacy, and small effects on increasing enjoyment and encouraging health behaviors [65]. Narrative game-based interventions provided through or promoted on social media could be a useful option to explore for tanning prevention efforts.

\section{Limitations and Future Directions}

As with any research, there are limitations to keep in mind with the current study. As we waited until the end of the ecological momentary assessment to elicit demographic information, demographic information was not available for a small proportion of participants. Additionally, while the sample came from 2 locations, it was a convenience sample that cannot be generalized more broadly. Additionally, we assessed only 6 emotions that participants may have felt, which were selected based on previous research related to tanning and social media use. Other emotions that were not captured in this study may have motivated participant behaviors. We also selected our time based on peak hours of UV exposure, so it is possible that there was social media use that occurred outside of our window of assessment, which could further impact findings associated with the role of emotions and social media use in particular. Perhaps emotions are stronger drivers of social media use only at certain times of day. We tried to mitigate the effects of a lack of data at certain time points in our creation of the composite variable, but we recognize that some instances of social media use were likely not captured, such as use during times that were outside our data collection efforts (eg, 11 PM) or on platforms that were not included (eg, Pinterest). However, the study does help advance the research in this area by using a different form of measurement through the use of ecological momentary assessment, allowing participants to report on media use, emotions, and behaviors closer in time to when they occurred, which should help reduce some of the potential difficulties of assessing dynamic constructs and issues with retrospective recall. However, although the analyses we conducted allowed us to assess the proposed research questions and hypotheses in a manner comparable to other research that has examined emotions, social media, and tanning in between-subject analyses $[5,7,47]$, this analytical decision did not allow us to look at within-person differences. Future work could benefit from the 
addition of within-person analyses to further address the connections between emotions, social media use, and tanning.

Future research would also benefit from looking at younger audiences, as research suggests adolescents may also be impacted by social media in regard to indoor tanning behaviors [5]. Examining more specific social media channels and their associations with tanning behaviors, as well as the content presented in social media, would also be beneficial. Previous research has found different associations with tanning behaviors based on specific platforms [6]. A greater understanding of the specific content to which young people are exposed could help further explain effects beyond mere exposure, as previous research in other topic areas has found that perceptions of media messages may be influential among young people [66,67]. Future research also should continue to explore the relationship between social media and tanning behaviors among young women to further parse out the mechanisms through which effects occur and to continue to bolster prevention efforts.
Additionally, more work in measurement, specifically for use in EMA studies, would be beneficial.

\section{Conclusion}

Our week-long ecological momentary assessment study of young women found that boredom, more than other emotional predictors, was associated with increased use of social media and that increased use of social media was associated with time spent outdoors without sun protection. This means that social media such as Snapchat, Instagram, Twitter, and Facebook may be prime channels for intervention and present an opportunity for reaching young women who have an increased risk of engaging in risky sun behaviors. Additionally, interventions developed for these channels should aim to be entertaining and engaging, as boredom was associated with social media use in our sample. By creating interventions that can entertain and educate, attention may be increased, potentially leading to greater intervention effects.

\section{Conflicts of Interest}

None declared.

\section{References}

1. Key statistics for melanoma skin cancer. American Cancer Society. URL: https://www.cancer.org/cancer/ melanoma-skin-cancer/about/key-statistics.html [accessed 2020-11-20]

2. Bleyer A, O'Leary M, Barr M, Ries L. Cancer epidemiology in older adolescents and young adults 15 to 29 years of age, including SEER incidence and survival: 1975-2000. National Cancer Institute Surveillance, Epidemiology, and End Results Program. 2006. URL: https://seer.cancer.gov/archive/publications/aya/ [accessed 2020-11-20]

3. Volkmer B, Greinert R. UV and children's skin. Prog Biophys Mol Biol 2011 Dec;107(3):386-388. [doi: 10.1016/j.pbiomolbio.2011.08.011] [Medline: 21907231]

4. Dennis LK, Lowe JB, Snetselaar LG. Tanning behavior among young frequent tanners is related to attitudes and not lack of knowledge about the dangers. Health Educ J 2009 Sep;68(3):232-243 [FREE Full text] [doi: 10.1177/0017896909345195] [Medline: 22707763]

5. Myrick JG, Noar SM, Kelley D, Zeitany AE. The relationships between female adolescents' media use, indoor tanning outcome expectations, and behavioral intentions. Health Educ Behav 2016 Sep 02;44(3):403-410. [doi: 10.1177/1090198116667251] [Medline: 27590838]

6. Willoughby JF, Myrick JG. Entertainment, social media use and young women's tanning behaviours. Health Educ J 2018 Dec 23;78(3):352-365. [doi: 10.1177/0017896918819643]

7. Niu Z, Parmar V, Xu B, Coups EJ, Stapleton JL. Prevalence and correlates of intentional outdoor and indoor tanning among adolescents in the United States: Findings from the FLASHE survey. Prev Med Rep 2018 Sep;11:187-190. [doi: 10.1016/j.pmedr.2018.06.014] [Medline: 29992085]

8. Lazarus RS. Progress on a cognitive-motivational-relational theory of emotion. Am Psychol 1991 Aug;46(8):819-834. [doi: 10.1037//0003-066x.46.8.819] [Medline: 1928936]

9. Roseman IJ. Emotional behaviors, emotivational goals, emotion strategies: multiple levels of organization integrate variable and consistent responses. Emotion Rev 2011 Sep 20;3(4):434-443. [doi: 10.1177/1754073911410744]

10. Stawski RS, Sliwinski MJ, Almeida DM, Smyth JM. Reported exposure and emotional reactivity to daily stressors: the roles of adult age and global perceived stress. Psychol Aging 2008;23(1):52-61. [doi: 10.1037/0882-7974.23.1.52] [Medline: $\underline{18361654]}$

11. Niederdeppe J. Meeting the challenge of measuring communication exposure in the digital age. Commun Methods Meas 2016 Apr 20;10(2-3):170-172. [doi: 10.1080/19312458.2016.1150970]

12. Eveland WP, Hutchens MJ, Shen F. Exposure, attention, or "use" of news? Assessing aspects of the reliability and validity of a central concept in political communication research. Commun Methods Meas 2009 Dec 09;3(4):223-244. [doi: 10.1080/19312450903378925]

13. Smyth JM, Stone AA. Ecological momentary assessment research in behavioral medicine. J Happiness Stud 2003;4(1):35-52. [doi: 10.1023/A:1023657221954]

14. Widén G, Lindström J, Brännback M, Huvila I, Nyström AG. Mixed emotions in active social media use - fun and convenient or shameful and embarrassing? 2015 Presented at: iConference 2015; March 24-27, 2015; Newport Beach, CA. 
15. Escobar-Viera CG, Shensa A, Bowman ND, Sidani JE, Knight J, James AE, et al. Passive and active social media use and depressive symptoms among United States adults. Cyberpsychol Behav Soc Netw 2018 Jul;21(7):437-443. [doi: 10.1089/cyber.2017.0668] [Medline: 29995530]

16. Berryman C, Ferguson CJ, Negy C. Social media use and mental health among young adults. Psychiatr Q 2018 Jun;89(2):307-314. [doi: 10.1007/s11126-017-9535-6] [Medline: 29090428]

17. Correa T, Hinsley AW, de Zúñiga HG. Who interacts on the web?: the intersection of users' personality and social media use. Comput Hum Behav 2010 Mar;26(2):247-253. [doi: 10.1016/j.chb.2009.09.003]

18. Forgas JP. Affect in social thinking and behavior. New York, NY: Psychology Press; 2006.

19. Choi M, Toma CL. Social sharing through interpersonal media: patterns and effects on emotional well-being. Comput Hum Behav 2014 Jul;36:530-541. [doi: 10.1016/j.chb.2014.04.026]

20. Stieglitz S, Dang-Xuan L. Emotions and information diffusion in social media—sentiment of microblogs and sharing behavior. J Manage Inf Syst 2013 Jun 7;29(4):217-248. [doi: 10.2753/MIS0742-1222290408]

21. Williams DL, Crittenden VL, Keo T, McCarty P. The use of social media: an exploratory study of usage among digital natives. J Public Aff 2012 Mar 06;12(2):127-136. [doi: 10.1002/pa.1414]

22. Kim K, Yoo-Lee E, Joanna Sin S. Social media as information source: undergraduates' use and evaluation behavior. 2011 Presented at: ASIST 2011: Annual Meeting of The American Society for Information Science and Technology; Oct 7-12, 2011; New Orleans, LA. [doi: 10.1002/meet.2011.14504801283]

23. Bolton RN, Parasuraman A, Hoefnagels A, Migchels N, Kabadayi S, Gruber T, et al. Understanding Generation Y and their use of social media: a review and research agenda. J Serv Manage 2013 Jun 14;24(3):245-267. [doi: 10.1108/09564231311326987]

24. Valkenburg PM, Peter J, Schouten AP. Friend networking sites and their relationship to adolescents' well-being and social self-esteem. Cyberpsychol Behav 2006 Oct;9(5):584-590. [doi: 10.1089/cpb.2006.9.584] [Medline: 17034326]

25. Potente S, Coppa K, Williams A, Engels R. Legally brown: using ethnographic methods to understand sun protection attitudes and behaviours among young Australians 'I didn't mean to get burnt--it just happened!'. Health Educ Res 2010 Nov 08;26(1):39-52. [doi: 10.1093/her/cyq066] [Medline: 21059798]

26. Feldman SR, Liguori A, Kucenic M, Rapp SR, Fleischer AB, Lang W, et al. Ultraviolet exposure is a reinforcing stimulus in frequent indoor tanners. J Am Acad Dermatol 2004 Jul;51(1):45-51. [doi: 10.1016/j.jaad.2004.01.053] [Medline: 15243523]

27. Myrick JG, Noar SM, Kelley D, Zeitany AE, Morales-Pico BM, Thomas NE. A longitudinal test of the Comprehensive Indoor Tanning Expectations Scale: the importance of affective beliefs in predicting indoor tanning behavior. J Health Psychol 2016 Jul 10;22(1):3-15. [doi: 10.1177/1359105315595116] [Medline: 26231616]

28. Yoo J, Hur W. Body-tanning attitudes among female college students. Psychol Rep 2014 Apr;114(2):585-596. [doi: 10.2466/06.07.pr0.114k21w5] [Medline: 24897909]

29. Carcioppolo N, Orrego Dunleavy V, Myrick JG. A closer look at descriptive norms and indoor tanning: investigating the intermediary role of positive and negative outcome expectations. Health Commun 2018 Sep 10;34(13):1619-1627. [doi: 10.1080/10410236.2018.1517632] [Medline: 30198759]

30. Noar SM, Myrick JG, Morales-Pico B, Thomas NE. Development and validation of the Comprehensive Indoor Tanning Expectations Scale. JAMA Dermatol 2014 May 01;150(5):512-521. [doi: 10.1001/jamadermatol.2013.9086] [Medline: 24500373]

31. Fredrickson BL. The role of positive emotions in positive psychology. The broaden-and-build theory of positive emotions. Am Psychol 2001 Mar;56(3):218-226 [FREE Full text] [Medline: 11315248]

32. Kourosh AS, Harrington CR, Adinoff B. Tanning as a behavioral addiction. Am J Drug Alcohol Abuse 2010 Jun 15;36(5):284-290. [doi: 10.3109/00952990.2010.491883] [Medline: 20545604]

33. Zillmann D. Mood management through communication choices. Am Behav Sci 2016 Jul 27;31(3):327-340. [doi: $10.1177 / 000276488031003005]$

34. Knobloch-Westerwick S. Mood management: theory, evidence, and advancements. In: Bryant J, Vorderer P, editors. Psychology of Entertainment. Mahwah, NJ: Lawrence Erlbaum Associates; 2006:239-254.

35. Dixon HG, Warne CD, Scully ML, Wakefield MA, Dobbinson SJ. Does the portrayal of tanning in Australian women's magazines relate to real women's tanning beliefs and behavior? Health Educ Behav 2011 Jan 24;38(2):132-142. [doi: 10.1177/1090198110369057] [Medline: 21263062]

36. Cho H, Lee S, Wilson K. Magazine exposure, tanned women stereotypes, and tanning attitudes. Body Image 2010 Sep;7(4):364-367. [doi: 10.1016/j.bodyim.2010.04.002] [Medline: 20573553]

37. Cafri G, Thompson JK, Roehrig M, Rojas A, Sperry S, Jacobsen PB, et al. Appearance motives to tan and not tan: evidence for validity and reliability of a new scale. Ann Behav Med 2008 Mar 21;35(2):209-220. [doi: 10.1007/s12160-008-9022-2] [Medline: 18365298]

38. Fogel J, Krausz F. Watching reality television beauty shows is associated with tanning lamp use and outdoor tanning among college students. J Am Acad Dermatol 2013 May;68(5):784-789. [doi: 10.1016/j.jaad.2012.09.055] [Medline: 23261546]

39. Social Media Use in 2018. Pew Research Center. URL: https://www.pewresearch.org/internet/2018/03/01/ social-media-use-in-2018/ [accessed 2020-11-20] 
40. Noar SM, Myrick JG, Zeitany A, Kelley D, Morales-Pico B, Thomas NE. Testing a social cognitive theory-based model of indoor tanning: implications for skin cancer prevention messages. Health Commun 2015;30(2):164-174. [doi: 10.1080/10410236.2014.974125] [Medline: 25470441]

41. Bandura A. Self-efficacy: toward a unifying theory of behavioral change. Psychol Rev 1977 Mar;84(2):191-215. [Medline: $\underline{847061]}$

42. Bandura A. Social Foundations of Thought and Action. Upper Saddle River, NJ: Prentice-Hall; 1986.

43. Rodríguez VM, Daniel CL, Welles BF, Geller AC, Hay JL. Friendly tanning: young adults' engagement with friends around indoor tanning. J Behav Med 2017 Feb 8;40(4):631-640. [doi: 10.1007/s10865-017-9832-4] [Medline: 28181003]

44. Moskowitz DS, Young SN. Ecological momentary assessment: what it is and why it is a method of the future in clinical psychopharmacology. J Psychiatry Neurosci 2006 Jan;31(1):13-20 [FREE Full text] [Medline: 16496031]

45. Sun safety. American Skin Association. URL: https://www.americanskin.org/resource/safety.php [accessed 2020-11-20]

46. Myrick JG, Holton AE, Himelboim I, Love B. \#Stupidcancer: exploring a typology of social support and the role of emotional expression in a social media community. Health Commun 2015 Oct 09;31(5):596-605. [doi: 10.1080/10410236.2014.981664]

47. Myrick J, Willoughby J. Beyond demographics: The relationship of young women's emotional states with skin damaging and skin safety behaviors. 2017 Presented at: Annual Meeting of the National Communication Association; Nov 16-19, 2017; Dallas, TX.

48. Kraus A, Myrick JG. Feeling bad about feel-good ads: the emotional and body-image ramifications of body-positive media. Commun Res Rep 2017 Oct 17;35(2):101-111. [doi: 10.1080/08824096.2017.1383233]

49. Miyamoto Y, Ma X. Dampening or savoring positive emotions: a dialectical cultural script guides emotion regulation. Emotion 2011 Dec;11(6):1346-1357. [doi: 10.1037/a0025135] [Medline: 21910543]

50. Hanwell H, Vieth R, Cole D, Scillitani A, Modoni S, Frusciante V, et al. Sun exposure questionnaire predicts circulating 25-hydroxyvitamin D concentrations in Caucasian hospital workers in southern Italy. J Steroid Biochem Mol Biol 2010 Jul;121(1-2):334-337. [doi: 10.1016/j.jsbmb.2010.03.023] [Medline: 20298782]

51. Diffey B, Norridge Z. Reported sun exposure, attitudes to sun protection and perceptions of skin cancer risk: a survey of visitors to Cancer Research UK's SunSmart campaign website. Br J Dermatol 2009 Jun;160(6):1292-1298. [doi: 10.1111/j.1365-2133.2009.09149.x] [Medline: 19416235]

52. Harrell F. Regression modeling strategies: With application to linear models, logistic and ordinal regression, and survival analysis. New York, NY: Springer International Publishing; 2015.

53. Eastwood JD, Frischen A, Fenske MJ, Smilek D. The unengaged mind: defining boredom in terms of attention. Perspect Psychol Sci 2012 Sep;7(5):482-495. [doi: 10.1177/1745691612456044] [Medline: 26168505]

54. Hill A, Perkins R. Towards a model of boredom. Br J Psychol 1985 May;76(2):235-240. [doi: 10.1111/j.2044-8295.1985.tb01947.x] [Medline: 4027489]

55. Mastro DE, Eastin MS, Tamborini R. Internet search behaviors and mood alterations: a selective exposure approach. Media Psychol 2002 May;4(2):157-172. [doi: 10.1207/s1532785xmep0402_03]

56. Tandoc EC, Ferrucci P, Duffy M. Facebook use, envy, and depression among college students: is facebooking depressing? Comput Hum Behav 2015 Feb;43:139-146. [doi: 10.1016/j.chb.2014.10.053]

57. Appel H, Gerlach A, Crusius J. The interplay between Facebook use, social comparison, envy, and depression. Curr Opinion Psychol 2016 Jun;9:44-49 [FREE Full text] [doi: 10.1016/j.copsyc.2015.10.006]

58. Holman DM, Watson M. Correlates of intentional tanning among adolescents in the United States: a systematic review of the literature. J Adolesc Health 2013 May;52(5 Suppl):S52-S59 [FREE Full text] [doi: 10.1016/j.jadohealth.2012.09.021] [Medline: 23601612]

59. Falzone AE, Brindis CD, Chren M, Junn A, Pagoto S, Wehner M, et al. Teens, tweets, and tanning beds: rethinking the use of social media for skin cancer prevention. Am J Prev Med 2017 Sep;53(3S1):S86-S94 [FREE Full text] [doi: 10.1016/j.amepre.2017.04.027] [Medline: 28818251]

60. Singhal A, Rogers E. Entertainment-education: A communication strategy for social change. New York, NY: Routledge; 2012.

61. Kim K, Lee M, Macias W. An alcohol message beneath the surface of ER: how implicit memory influences viewers' health attitudes and intentions using entertainment-education. J Health Commun 2014;19(8):876-892. [doi: 10.1080/10810730.2013.837556] [Medline: 24479746]

62. van Leeuwen L, Renes RJ, Leeuwis C. Televised entertainment-education to prevent adolescent alcohol use: perceived realism, enjoyment, and impact. Health Educ Behav 2013 Apr;40(2):193-205. [doi: 10.1177/1090198112445906] [Medline: 22773596]

63. Willoughby JF, Liu S. Do pictures help tell the story? An experimental test of narrative and emojis in a health text message intervention. Comput Hum Behav 2018 Feb;79:75-82. [doi: 10.1016/j.chb.2017.10.031]

64. Willoughby JF, Niu Z, Liu S. Assessing the potential use of narrative and the entertainment education strategy in an mHealth text-message intervention. J Health Commun 2018;23(1):20-27. [doi: 10.1080/10810730.2017.1396628] [Medline: 29252131]

65. Zhou C, Occa A, Kim S, Morgan S. A meta-analysis of narrative game-based interventions for promoting healthy behaviors. J Health Commun 2020;25(1):54-65. [doi: 10.1080/10810730.2019.1701586] [Medline: 31829829] 
66. Rodgers KB, Hust SJT, Willoughby JF, Wheeler J, Li J. Adolescents' sex-related alcohol expectancies and alcohol advertisements in magazines: the role of wishful identification, realism, and beliefs about women's enjoyment of sexualization. J Health Commun 2019;24(4):395-404. [doi: 10.1080/10810730.2019.1630523] [Medline: 31215356]

67. Willoughby JF, Hust SJT, Li J, Couto L. Social media, marijuana and sex: an exploratory study of adolescents' intentions to use and college students' use of marijuana. J Sex Res 2020 Oct 09:1-13. [doi: 10.1080/00224499.2020.1827217] [Medline: $\underline{33034543]}$

\section{Abbreviations}

EMA: ecological momentary assessment

FLASHE: Family Life, Activity, Sun, Health, and Eating

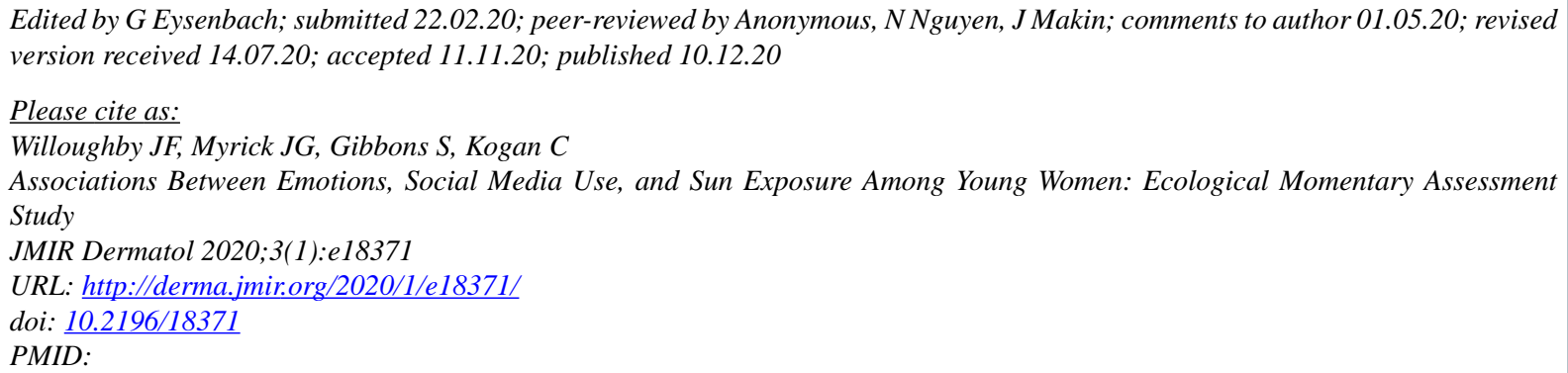

CJessica Fitts Willoughby, Jessica Gall Myrick, Stephanie Gibbons, Clark Kogan. Originally published in JMIR Dermatology (http://derma.jmir.org), 10.12.2020. This is an open-access article distributed under the terms of the Creative Commons Attribution License (https://creativecommons.org/licenses/by/4.0/), which permits unrestricted use, distribution, and reproduction in any medium, provided the original work, first published in JMIR Dermatology Research, is properly cited. The complete bibliographic information, a link to the original publication on http://derma.jmir.org, as well as this copyright and license information must be included. 